\begin{tabular}{|c|c|}
\hline \multirow{3}{*}{ 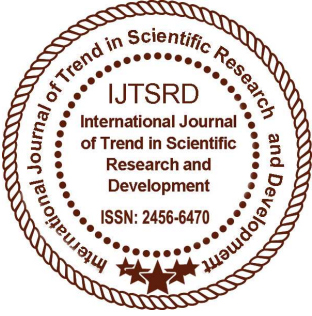 } & $\begin{array}{l}\text { International Journal of Trend in Scientific } \\
\text { Research and Development (IJTSRD) }\end{array}$ \\
\hline & International Open Access Journal \\
\hline & ISSN No: 2456 - 6470 | www.ijtsrd.com | Volume - 2 | Issue - 4 \\
\hline
\end{tabular}

\title{
Review Paper on Improved Exhaust Emission Control by The Use of Cu-Zeolite Catalyst Based Catalytic Converter
}

\author{
Akash Pathak, K. Venkadeshwaran, Alok Kumar Rohit, Niranjan Kumar Naulakha \\ Department of Mechanical Engineering, SET, Jain University, Bengaluru, India
}

\begin{abstract}
In the present time, the automobiles running on the roads have drastically increased in number due to the advancement in the sector with low cost to offer to the people. Though this has made the life sophisticated as well as has made our life easier in terms of travelling and transportation, this has dragged us towards a major issue regarding the pollution it causes to the atmosphere. The compression ignition engine that are used in the vehicles produces a large amount of obnoxious gases like $\mathrm{NO}_{\mathrm{X}}, \mathrm{HC}, \mathrm{CO}$, etc. The existing catalytic converter that is used in order to convert this harmful gases are not meeting the demands of euro 6 emission standards as well as they are inadequate to work in very high temperature. In order overcome this issue and make the system more efficient, the existing catalytic converter's ceramic structure can be modified by applying a wash coat of $\mathrm{Cu}$-Zeolite catalyst to it which results in lower $\mathrm{NO}_{\mathrm{X}}$ emission even at high exhaust temperature.
\end{abstract}

Keywords: Catalytic Converter, Exhaust emission, Euro 6 Standards, Cu-Zeolite Catalyst

\section{INTRODUCTION}

\subsection{Emission Control:}

Though there are many other alternatives to run vehicles such as electricity, solar energy, etc., the fuels such as diesel, petrol and gasoline are regarded as the most efficient means. But these fuels don't completely burn inside the combustion chamber and thus result in different products of combustion. The gas coming out of exhaust of a combustion chamber having following composition:

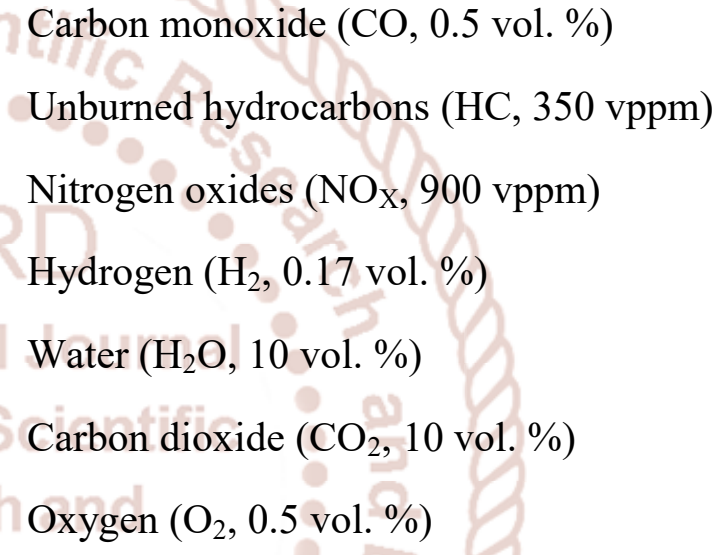

Carbon monoxide (CO, 0.5 vol. \%)

Unburned hydrocarbons (HC, 350 vppm)

Nitrogen oxides $\left(\mathrm{NO}_{\mathrm{X}}, 900 \mathrm{vppm}\right)$

Hydrogen $\left(\mathrm{H}_{2}, 0.17\right.$ vol. \%)

Water $\left(\mathrm{H}_{2} \mathrm{O}, 10\right.$ vol. \%)

Carbon dioxide $\left(\mathrm{CO}_{2}, 10\right.$ vol. \%)

Oxygen $\left(\mathrm{O}_{2}, 0.5\right.$ vol. \%)

Out of the above mentioned, the products like $\mathrm{NO}_{\mathrm{X}}$, $\mathrm{CO}$ and $\mathrm{HC}$ are very harmful to the environment and ultimately all the living beings. They are considered as one of the main reason for air pollution. The gases like $\mathrm{HC}$ and $\mathrm{CO}$ are produced because no engine has a combustion efficiency of $100 \%$ and is always less than it as well as the effects of the quenching at the walls of the engine cylinder which is at lower temperature. On the other hand, if the temperature of the combustion process rises over $1500^{\circ} \mathrm{C}$ it leads to thermal nitrogen fixation in the air which results in the formation of $\mathrm{NO}_{\mathrm{X}}$. [1]

\section{LITERATURE SURVEY}

Mr. Mukul M Khalasane et al. [2] explains that among every one of the kinds of innovations grew up until now, utilization of Metal monolith type converter in exhaust systems is the best approach to control auto fumes emission. Three way exhaust system utilizing respectable gathering metal with stoichiometric motor control framework have been 
produced for use on transports, trucks, and bikes and also on rough terrain vehicles. Narendrasinh R. Makwana et al. [3] summarise about selective catalytic converter (SCR) innovation concerning mileage, the prerequisite of a rich consume engine to run at a the stoichiometric point at implies utilizes more fuel than a "lean consume" engine running at a blend of 20:1 or less. Be that as it may, NOx control on lean consume engine is difficult. However, the Specific Selective catalytic converter (SCR) innovation with the capacity to convey close to zero discharges of Nitrogen Oxides (NOx). Ankush Ghodke et al. [4] this paper gives the information about by consolidating the residue filter and selective catalytic convertor, it will fulfill the objective i.e. low weight-volume proportion and High NOx reduction in high temperature. Changing the catalytic convertor may solve the issues and the euro 6 emanation standards will be fulfilled. Julie M Pardiwala et al. [5] shows limited availability, cost and some working conditions have propelled the research on alternate catalyst material. Michael Rice et al. [6] shows the rules and laws with regard to emission from the diesel engine that have changed in the last two decades along with the ways to reduce exhaust emission using SCR combined with soot filter. Yisun cheng et al. [7] illustrates concerns regarding sulphur poisoning in the system incorporating Diesel Oxidation Catalyst for applications of diesel engine ahead of $\mathrm{Cu} / \mathrm{Zeolite}$ Selective catalytic reduction (SCR) catalyst.

\section{CATALYTIC CONVERTER}

Catalytic converter is a setup installed in the exhaust pipe of the engine which converts the toxic gases into less harmful ones. The harmful gases emitting from the combustion of gasoline and diesel have hazardous effect on human life as well as on atmosphere. These gases mainly include $\mathrm{CO}, \mathrm{HC}$ and $\mathrm{NO}_{\mathrm{X}}$. It was invented by a French Mechanical engineer Eugene Houdry in the year 1950, In order to control these harmful emissions catalytic converters are used. Different alternatives are examined to control the harmful exhaust gases such as by blending additives with fuel, modifying engine design, pretreatment of fuel, treatment of exhaust gases. The catalytic converter is the best suited option for reducing the exhaust emissions level from vehicles among all the available options till date. The catalysts in catalytic converter turns poisonous gases like $\mathrm{CO}, \mathrm{HC}$ and $\mathrm{NO}_{\mathrm{X}}$ into $\mathrm{CO}_{2}, \mathrm{H}_{2} \mathrm{O}, \mathrm{N}_{2}$, and $\mathrm{O}_{2}$.

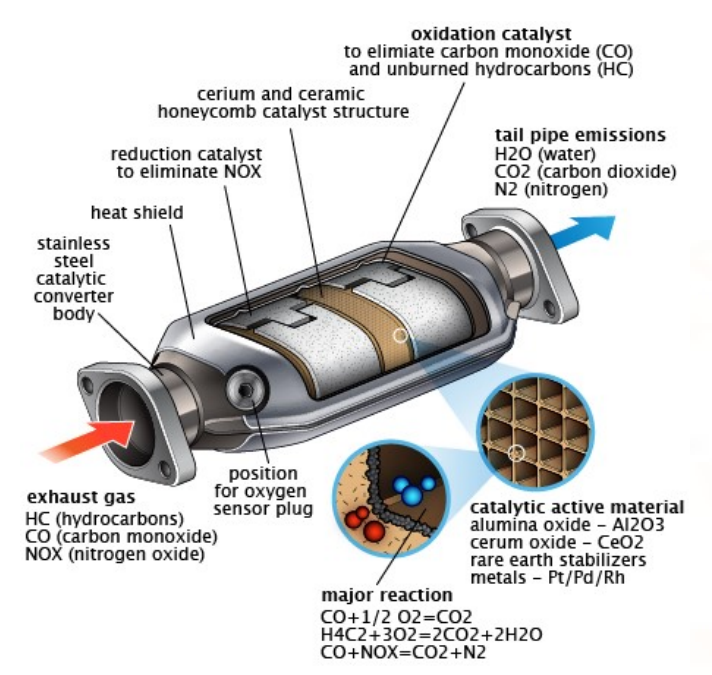

Fig 1: Catalytic Converter

\subsection{Major parts of Catalytic Converter}

a) Stainless Steel Housing:

It gives adequate frame support and protection to the substrate. Insulating materials with seals are provided to protect the material from burn out. Insulating materials are generally made up of metal wire mesh.

\section{b) Substrate:}

Substrate is a porous ceramic honeycomb structure installed inside the converter made of metal wire (stainless steel). It works as a support system and also known as catalyst support developed by Rodney Bagley, Irwin Lachman and Ronald Lewis for providing maximum surface exposure to exhaust gases.

\section{c) Washcoat:}

Composition of Alumina and silica is used as washcoat for making the converter to work more efficiently compared to flat core surfaces introducing washcoat to substrate gives more surface exposure for sits to active noble metals which is being added to washcoat before its use on substrate.

\section{d) Catalyst:}

Catalyst is a noble group metal used in catalytic converter and is very costly. Platinum, Palladium, and Rhodium is the most widely used metals as active catalyst worldwide. For secondary reaction to occur another costlier metal called Rhodium is used. For oxidation reaction to occur Platinum and Palladium are used as well as for reduction reaction Platinum and Rhodium are used. Based on the reaction 
occurring in the converter, they are of following main types:

\section{1) Oxidation reaction / Two way catalytic converter:}

As it deals only with unburnt and partially burnt fuel i.e. hydrocarbons and carbon monoxide, it is known as two way catalytic converter. Here carbon monoxide gets oxidized to carbon dioxide and hydrocarbons gets oxidized to carbon dioxide and water. Hence it is known as oxidation reaction. In this method the oxidation reaction takes place by using aluminum oxide deposited with platinum on a support material and the entire unit is placed in the exhaust stream of combustion chamber. When carbon monoxide and hydrocarbons passes through it following reaction takes place:

a) Carbon monoxide (partially burnt) oxidizes to carbon dioxide

$2 \mathrm{CO}+\mathrm{O}_{2} \rightarrow 2 \mathrm{CO}_{2}$

b) Hydrocarbon (unburnt) oxidizes to carbon dioxide and water

$$
\mathrm{C}_{\mathrm{n}} \mathrm{H}_{2 \mathrm{n}+2}+[(3 \mathrm{n}+1) / 2] \mathrm{O}_{2} \rightarrow \mathrm{nCO}_{2}+(\mathrm{n}+1) \mathrm{H}_{2} \mathrm{O}
$$

\section{2) Reduction reaction $/$ Three way catalytic} converter:

In this type of catalytic converter, along with hydrocarbons and carbon monoxides, the $\mathrm{NO}_{\mathrm{X}}$ emission is also converted into less harmful gases. $\mathrm{NO}_{\mathrm{X}}$ gas emission is produced at high temperature i.e. more than $1500^{\circ} \mathrm{C}$. Here, both oxidation and reduction reaction takes place and both oxidation and reduction catalysts are present in the same housing except in some cases where there are present separately. Here, the following reactions takes place:

a) Reduction of nitrogen oxides to nitrogen and oxygen:

$2 \mathrm{NO}_{\mathrm{n}} \rightarrow \mathrm{nO}_{2}+\mathrm{N}_{2}$

b) Oxidation of carbon monoxide to carbon dioxide:

$2 \mathrm{CO}+\mathrm{O}_{2} \rightarrow 2 \mathrm{CO}_{2}$

c) Oxidation of unburnt hydrocarbons (HC) to carbon dioxide and water:

$\mathrm{C}_{\mathrm{n}} \mathrm{H}_{2 \mathrm{n}+2}+[(3 \mathrm{n}+1) / 2] \mathrm{O}_{2} \rightarrow \mathrm{nCO}_{2}+(\mathrm{n}+1) \mathrm{H}_{2} \mathrm{O}$

\subsection{Working of a Catalytic Converter:}

Out of the above mentioned types of catalytic converter, the most widely used type is three-way catalytic converter. This is because here along with oxidation reaction, reduction of $\mathrm{NO}_{\mathrm{X}}$ is also accompanied with size of the catalytic converter almost remaining the same.[8] As discussed above in the three way catalytic converter, both reduction catalyst and oxidation catalyst are employed. In this type, platinum, rhodium and/or palladium (noble metals) are coated on a ceramic structure because this type of structure provides larger surface area to the exhaust stream.

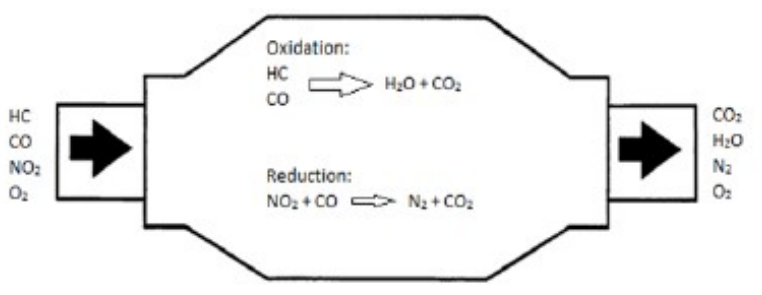

Fig 2: Working of Catalytic Converter

Here, platinum and rhodium catalysts are present in the first stage of the converter where reduction reaction takes place i.e. $\mathrm{NO}_{\mathrm{X}}$ emission is converted into stable nitrogen and oxygen which are not harmful. Similarly, oxidation reaction takes place in the second stage where hydrocarbons and carbon monoxide gets oxidized to water and carbon dioxide by burning the hydrocarbons and carbon monoxide passing it over a platinum and palladium catalyst. [9]

\subsection{Problems in the existing catalytic converter:}

\section{1) High weight to volume ratio:}

It is desired to have a light weight catalytic converter because increase in its weight results ultimately increases the weight of the vehicles. But the conventional catalytic converter has high weight to volume ratio which increases the weight of the vehicle and increases the consumption of fuel to drive the vehicle.

\section{2) Low working range of catalysts:}

The catalysts i.e. platinum and palladium used for the reduction of $\mathrm{NO}_{\mathrm{X}}$ have very low working range. Hence, at very high temperature the $\mathrm{NO}_{\mathrm{X}}$ emission produced is not completely reduced and is emitted to 
the atmosphere from the exhaust which make the catalytic converter inefficient.

\section{3) Inability of the converter to meet the Euro 6 norms:}

The euro 6 norms that were used earlier have been changed and the $\mathrm{NO}_{\mathrm{X}}$ emission standards have been reduced. But the existing catalytic converter doesn't meet the euro 6 norms as the emission of the $\mathrm{NO}_{\mathrm{X}}$ is comparatively higher which makes it necessary to modify the converter to meet the norms.

\section{4) High back pressure:}

The conventional catalytic converter have a major back pressure problem which leads to other different problems resulting in decreased engine performance and high fuel consumption. If the back pressure is increased to much larger extent it may also cease the engine completely.

\subsection{Improvement in the existing Catalytic Converter}

All the above problems arise mainly due to the catalyst that is used in order to trigger the reaction. Therefore, introducing a new catalyst instead of the existing ones which can work better in terms of triggering the reaction as well as solve the above mentioned problems would be the main objective while modifying the catalytic converter. So, the idea would be to merge the soot filter and monolith structure's SCR layers with a new catalyst i.e. CuZeolite. $\mathrm{Cu}$-Zeolite comprises of two main chemicals which are:

1. Zeolite powder (ZSM 5)

2. Cupric acetate hydrate

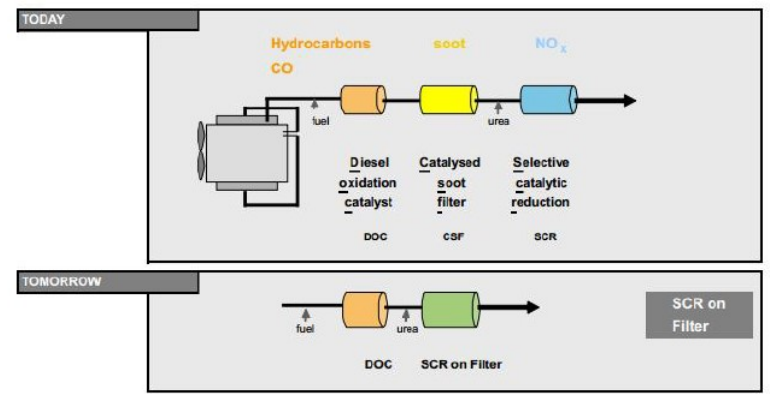

Fig 3: Schematic of Improved Catalytic Converter
Introducing a new catalyst will not be enough to tackle all the problems with the conventional catalytic converter because of its complexity. So, it is also important to a catalytic converter that would be simple in design as well as smart in operation. In order to achieve this, the most feasible way would be to combine Catalyst Soot Filter (CSF) and Selective Catalytic Reduction (SCR) as one component by placing SCR's active mass on the CSF's filter substrate. The integrated system as a whole is known as SCR on filter or simple SCROF which abbreviates to Selective Catalytic Reduction on Filter. This combination when used for diesel engine would reduce the $\mathrm{NO}_{\mathrm{X}}$ emission as per the Euro 6 norms. In simple terms, SCROF is the integration of two types of existing diesel exhaust system viz. SCR and CSF which are solely inefficient to reduce the $\mathrm{NO}_{\mathrm{X}}$ emission to desired level.

\section{CONCLUSION}

Among all the available catalyst used in the catalytic converter, the $\mathrm{Cu}$-Zeolite stands as the ideal catalyst to overcome the problems seen in the conventional catalytic converter as well as improving the performance of the engine and CI engine's emission parameters. On the other hand, the combination of the CSF and CSR would lead to solve the problem of high weight to volume ratio and low $\mathrm{NO}_{\mathrm{X}}$ reduction of the earlier available converters. It would also help to achieve the main objective of meeting the Euro 6 norms.

\section{ACKNOWLEDGEMENT}

The authors wish to acknowledge the support provided by the School of Engineering and Technology, Jain University, Bangalore in preparation of this manuscript.

\section{REFERENCES}

1. R. M. Kakwani, K.Voss, J. Patchett \& K.Grimston Engelhard, "Combined Catalyzed Soot Filter and SCR Catalyst system for Diesel Engine Emission Reduction".6th diesel engine emission reduction (DEER) workshop, August 20, 2000 San Diego, California.

2. Mukul M Khalasane, "A review paper on catalytic converter for automatic exhaust emission."

3. Narendrasinh R. Makwana, Prof. Shyam K. Dabhi, "Automotive Exhaust Technology after 
Treatment for the Reduction of Emission-A Review Study."

4. Ankush Ghodke, Ganesh Gage, Amol Madane, Avinash Shinare, Naik K.S., "Improved Catalytic Convertor for CI Engine Emission Control System."

5. Julie M Pardiwala, Femina Patel, Sanjay Patel, "Review paper on Catalytic Converter for Automotive Exhaust Emission."

6. Michael Rice, Jan Kramer, Klaus Mueller-Haas, Raimund Mueller. "Innovative Substrate Technology for High Performance Heavy Duty Truck SCR Catalyst Systems". 2007 SAE International.
7. Yisun Cheng, Christine Lambert, Do Heui Kim, Ja Hun Kwak, Charles H.F. Peden, "Investigation of Sulfur Deactivation on $\mathrm{Cu} /$ Zeolite SCR Catalysts in Diesel Application”. August 4, 20092009 DEER Conference.

8. Hans-Dieter Harder, Marc Braggers, Rolf Brück, "Future SCR NOX Aftertreatment Systems for Euro 6."

9. Dr. R. Samuel Boors', Dr. Martin Diatreme, Dr. Kenneth Voss, Dr. Susanne Stiebels, Dr. Claudia Wendt, Dr. Torsten Neubauer, "Two in One: SCR on Filter". BASF Catalysts Germany GmbH; Freundallee 23, 30173 Hannover." 